\title{
Household Food Waste Behavior: Avenues for Future Research
}

\author{
GUSTAVO PORPINO
}

\begin{abstract}
Drawing from previous studies, this review proposes a research agenda in regard to household food waste, a neglected topic within the field of consumer behavior. This phenomenon has remarkable social and environmental relevance when one considers that it occurs at the end of the food chain, and thus, wastage at this stage implies losses of resources required for food production. This study aims to provide a framework and solutions for conducting future research in this area. Academic opportunities identified suggest that further theorizing is needed related to consumer food waste, in addition to studies aimed at testing the impact of communication initiatives on behavioral change and at providing a standardized methodology to measure consumer food waste.
\end{abstract}

$\square$ ood waste, as a line of research, provides the opportunity for scholarly work in marketing to meet the criteria of managerial, public policy, and societal relevance. In a world facing climate change, scarcity of natural resources (e.g., water shortage in California and São Paulo), and increasing consumption in developing nations, consumer studies can contribute to identifying ways of changing behavior that will benefit society at large. The reduction of food waste-especially in staple commodity foods such as rice - is seen as a key leverage point for improving global food security and environmental sustainability (West et al. 2014).

Household food waste studies are growing in frequency, as seen in figure 1. Since the Food and Agriculture Organization of the United Nations (FAO) stated that roughly one-third of the food produced in the world is discarded (Gustavsson et al. 2011; FAO 2013), academics have attempted to explain why the majority of wasted food in developed nations is a product of consumer behavior (e.g., Quested et al. 2013; Stefan et al. 2013; Graham-Rowe, Jessop, and Sparks 2014; Leal Filho and Kovaleva 2015).

This review calls for more attention to food waste as a research topic within the consumer behavior literature. At this time, food waste research is "boundary research" (Wansink and van Ittersum 2016), that is, multidisciplinary. Drawing from an analysis of the literature, new avenues for future re- search are outlined. After briefly analyzing the drivers of household food waste, these key opportunities for future research are identified along with specific challenges and specific solutions to these challenges.

\section{WASTE, AWARENESS, AND CHANGE}

The magnitude of household food waste is almost incalculable given that edible food might not simply be thrown in the trash, but served to pets, composted in a bin or even dumped in a garden. Therefore, efforts to measure wasted food tend to underestimate actual values (Foresight 2011). In order to provide approaches to this problem and generate theoretical contributions, attention should be given to explaining why consumers waste edible food, versus quantifying the amount wasted. Nevertheless, estimations are important to identify to what extent consumer food waste is an issue in certain countries.

As the baby boomers have matured, the awareness of the value of food seems to have diminished. Empirical evidence shows that European countries that faced a lack in the availability of various foods in times of war have replaced their mentality of resourcefulness with a pattern of waste. In Germany, for instance, households are estimated to waste $47 \%-$ $65 \%$ of the total wastage along the food chain (Leal Filho and Kovaleva 2015), while the average for the European Union (EU) is $42 \%$ (Katsarova 2014).

Gustavo Porpino (gustavo.porpino@embrapa.br) holds a PhD in marketing from Getulio Vargas Foundation (FGV-EAESP), and works for the Brazilian Agricultural Research Corporation (Embrapa), PqEB, W3 Norte-Asa Norte, Brasilia-DF 70770-901, Brazil. The author is grateful for the financial support of the Brazilian Agriculture Research Corporation (Embrapa) and the Cornell Food and Brand Lab. Special thanks to Juracy Parente for his valuable comments on earlier drafts of this study and to Brian Wansink and his team, who have collaborated with the author during his period at Cornell University as a visiting scholar.

JACR, volume 1, number 1. Published online January 1, 2016. http://dx.doi.org/10.1086/684528

(C) 2016 the Association for Consumer Research. All rights reserved. 2378-1815/2016/0101-0004\$10.00 
Food waste papers published by period

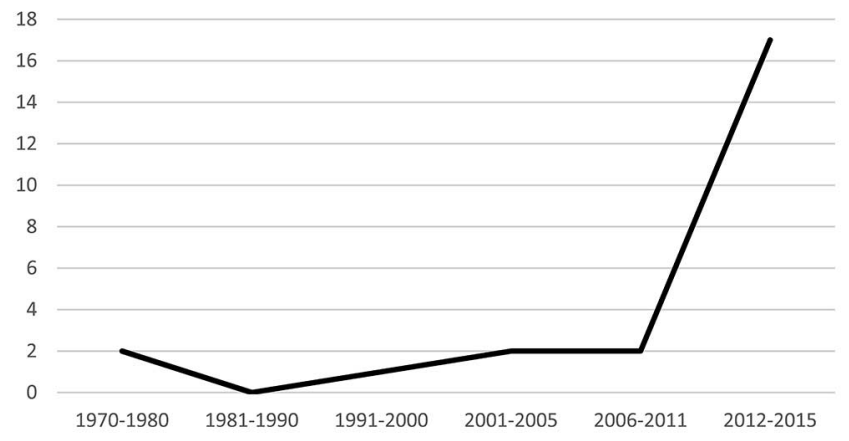

Figure 1. Peer-reviewed papers on household food waste.

Data on consumer food waste are often fragmented, and disparities are perceived among various studies. While the European Commission (2010) estimated household food waste per capita in EU countries to be $76 \mathrm{~kg} /$ year, with Netherlands (113 kg), France, and Sweden (100 kg) presenting wastage patterns above average, more recently, Vanham et al. (2015) projected EU consumer food waste at $123 \mathrm{~kg}$ (cap/yr), and Katsarova (2014) cited an increase in household food waste from $33 \mathrm{~kg}$ (cap/yr) in 2004 to $52 \mathrm{~kg}$ (cap/yr) in 2010.

In response to the need to mitigate food waste, several countries are taking action to increase the awareness of food waste via campaigns, such as the "Love Food Hate Waste" from the WRAP in the United Kingdom and the worldwide initiative "Think.Eat.Save" from the United Nations Environment Programme (UNEP), Food and Agricultural Organization of the United Nations (FAO), and Messe Dusseldorf. Several nongovernmental organizations (NGOs) are also working to increase the utilization of foods at the consumer level. The Robin Hood Army (India), Food Angel (Hong Kong), Re-food (Portugal), OzHarvest (Australia), Mesa Brasil (Brazil), and Rolling Harvest Food Rescue (USA) are examples of initiatives that collect food products from retailers or individuals for donation to food banks, food pantries, or directly to people in need.

Furthermore, retailers are also more responsive to the need for offering doggy bags and half-sized portions in restaurants. The Satisfeito (satisfied) movement in Brazil and Mexico, for instance, promotes the "Satisfeito Version," which is a portion two-thirds of the normal size, offered at the same price as a full portion, and is featured on the menu alongside the campaign logo. What the restaurant saves with reduced servings is transferred to hunger relief programs of international organizations. In addition, supermarkets from the United States and Europe are introducing new bulk foods sections, in which consumers might buy only what they need of certain grains or even of olive oil. I assume that these nonprepackaged goods fill the niche of offering portions appropriate to single-person households.

A strong motive for academic studies to shed more light on this topic is provided when we consider that a hypothetical reduction in food production, as a result of less wastage, appears to be a good solution for resource efficiency and environmental impacts, but "in practice it is not attractive to the business objectives or to the existing economic systems" (Grizzetti et al. 2013, 193). It is clear that food waste both influences and is influenced by many aspects of economics, consumer behavior, and societal well-being, and it deserves more study.

\section{INSIGHTS FOR FUTURE IMPACTFUL RESEARCH}

The literature focused on household food waste was almost nonexistent until the start of the current century. It was only around 2012 that the first analytical studies appeared. As presented in table 1, this study has identified 24 papers on household food waste. By analyzing the data they provide, several research opportunities have arisen. As noted by Stefan et al. (2013), acquiring a deeper understanding of food waste, and its relation to the food-provisioning process within households, demands more research on how consumers develop and use food-related skills. For Ekström (2015), although food waste is a practical problem, theorizing about it is necessary in order to comprehend it and to promote a more sustainable society.

For the purposes of this analysis, we consider "wasted food" to be any food produced for human consumption that is discarded, whether it was kept beyond its expiry date, left to spoil, or thrown away for any reason (FAO 2013). Thus, if a family, for instance, chooses to feed pets with leftovers, an appropriate means to discard food might have been reached, but waste itself was not avoided.

It is known that planning and shopping routines (Stefan et al. 2013) are important predictors of food waste. Overpreparation (Kantor et al. 1997; Quested and Johnson 2009; Koivupuro et al. 2012; Williams et al. 2012; Beretta et al. 2013; Porpino, Parente, and Wansink 2015) and excessive purchase (Harrison et al. 1975; Koivupuro et al. 2012; Beretta et al. 2013; Ganglbauer, Fitzpatrick, and Comber 2013; Porpino et al. 2015) are the most salient factors already mentioned in the literature as antecedents of wasted food. Table 2 identifies antecedents of food waste mentioned 
Table 1. Previous Peer-Reviewed Studies on Household Food Waste

\begin{tabular}{|c|c|c|c|}
\hline Reference & Country & Findings & Journal \\
\hline Neff, Spiker, and Truant (2015) & USA & $\begin{array}{l}\text { Saving money and setting an example for children identified as leading } \\
\text { motivations for waste reduction. Concern about food-borne illness and } \\
\text { a desire to eat only the freshest food as the core reasons for discarding } \\
\text { food. }\end{array}$ & $P O$ \\
\hline $\begin{array}{l}\text { Parizeau, Massow, and Martin } \\
\text { (2015) }\end{array}$ & Canada & $\begin{array}{l}\text { Food awareness, waste awareness, family lifestyles, and convenience life- } \\
\text { styles identified as related to food waste production. }\end{array}$ & $W M$ \\
\hline Porpino et al. (2015) & Brazil & $\begin{array}{l}\text { Excessive purchasing, overpreparation, caring for a pet, avoidance of } \\
\text { leftovers, and inappropriate food conservation identified as the major } \\
\text { antecedents of wasted food in the low-income context. }\end{array}$ & IJCS \\
\hline Tucker and Farrelly (2015) & New Zealand & $\begin{array}{l}\text { Food waste increases according to the number of individuals in a house- } \\
\text { hold, and in particular the number of younger people. }\end{array}$ & $L E$ \\
\hline $\begin{array}{l}\text { Farr-Wharton, Foth, and Choi } \\
\quad(2014)\end{array}$ & Australia & $\begin{array}{l}\text { Supply knowledge, ability to locate food items, and food literacy are } \\
\text { identified as core drivers of wasted food. }\end{array}$ & $J C B$ \\
\hline Graham-Rowe et al. (2014) & UK & $\begin{array}{l}\text { Desire to avoid experiencing negative emotions motivates avoiding waste. } \\
\text { Four core categories of barriers to minimizing food waste were identi- } \\
\text { fied: a "good" provider identity, minimizing inconvenience, lack of pri- } \\
\text { ority, and exemption from responsibility. }\end{array}$ & $R C R$ \\
\hline $\begin{array}{l}\text { Abeliotis, Lasaridi, and Chroni } \\
\text { (2014) }\end{array}$ & Greece & $\begin{array}{l}\text { Consumers show positive attitudes toward food waste prevention, but } \\
\text { about } 40 \% \text { misunderstand the meaning of expiration/sell-by date labels. }\end{array}$ & $W M R$ \\
\hline Silvennoinen et al. (2014) & Finland & $\begin{array}{l}\text { Identifies spoilage (e.g., mold), plate leftovers, and preparing more food } \\
\text { than needed as main reasons for discarding food. }\end{array}$ & $B F J$ \\
\hline Quested et al. (2013) & UK & $\begin{array}{l}\text { Food waste prevention has less visibility to others (e.g., neighbors) than } \\
\text { other pro-environmental behaviors (e.g., recycling), and therefore social } \\
\text { norms around "waste" play a reduced role compared to more "visible" } \\
\text { activities. }\end{array}$ & $R C R$ \\
\hline Stefan et al. (2013) & Romania & $\begin{array}{l}\text { Consumers' planning and shopping routines are important predictors of } \\
\text { food waste. Planning and shopping routines are determined by moral } \\
\text { attitudes toward food waste and perceived behavioral control. }\end{array}$ & $F Q P$ \\
\hline Ganglbauer et al. (2013) & Austria/UK & $\begin{array}{l}\text { Food waste is the unintended result of multiple moments of consumption } \\
\text { dispersed in space and time across other integrated practices such as } \\
\text { shopping and cooking, which are themselves embedded in broader } \\
\text { contextual factors and values. }\end{array}$ & TOCHI \\
\hline $\begin{array}{l}\text { Wansink and van Ittersum } \\
\text { (2013) }\end{array}$ & USA & $\begin{array}{l}\text { Visual consumption norms influence how much food we serve and waste } \\
\text { on different sized dinnerware. Large plates result in more food served } \\
\text { and more wasted food. }\end{array}$ & JEP \\
\hline Oelofse and Nahman (2013) & South Africa & $\begin{array}{l}\text { Overall food waste, in South Africa, is estimated at } 177 \mathrm{~kg} / \text { capita/year and } \\
\text { consumption waste at } 7 \mathrm{~kg} / \text { capita/year. }\end{array}$ & $W M R$ \\
\hline Koivupuro et al. (2012) & Finland & $\begin{array}{l}\text { Household size, the gender of the individual responsible for grocery } \\
\text { shopping, the frequency of buying discounted food products, the re- } \\
\text { spondent's own view of the potential to reduce food waste and the } \\
\text { respondent's own view of the influence of purchasing particular food } \\
\text { packet sizes influence the amount of food wasted. }\end{array}$ & IJCS \\
\hline Williams et al. (2012) & Sweden & $\begin{array}{l}\text { Around } 20 \%-25 \% \text { of the households' food waste could be related to big or } \\
\text { difficult-to-empty packages, and wastage due to "best before" date. }\end{array}$ & $J C P$ \\
\hline Evans (2012b) & UK & $\begin{array}{l}\text { Disposal of surplus food is enacted via a graduated process in which it first } \\
\text { enters a "gap" where ambiguities and anxieties surrounding its residual } \\
\text { value and onward trajectory are addressed. }\end{array}$ & SOC \\
\hline Nahman et al. (2012) & South Africa & $\begin{array}{l}\text { Household food waste alone costs South African society an estimated } \\
\text { US } \$ 2.7 \text { billion per year. }\end{array}$ & $W M$ \\
\hline
\end{tabular}


Table 1. (Continued)

\begin{tabular}{|c|c|c|c|}
\hline Reference & Country & Findings & Journal \\
\hline Evans (2011) & UK & $\begin{array}{l}\text { Household food waste cannot be conceptualized as a problem of individual } \\
\text { consumer behavior. }\end{array}$ & $\mathrm{CPH}$ \\
\hline Evans (2012a) & UK & $\begin{array}{l}\text { The passage of food into waste arises as a consequence of the ways in } \\
\text { which domestic practices are socially and materially organized. }\end{array}$ & SOC \\
\hline Terpstra et al. (2005) & Netherlands & $\begin{array}{l}\text { Consumers tend to be more careful with the storage of meat, sliced cold } \\
\text { meats, and dairy products than with vegetables, fruit juices, and left- } \\
\text { overs. }\end{array}$ & BFJ \\
\hline Bolaane and Ali (2004) & Botswana & $\begin{array}{l}\text { Waste generation rate was not directly related to household income. } \\
\text { Packaging fractions of plastic and paper measured as volume had a di- } \\
\text { rect relationship with household income. }\end{array}$ & $W M R$ \\
\hline Thogersen (1996) & USA/Mexico & $\begin{array}{l}\text { Growth in household solid waste in industrialized countries can be satis- } \\
\text { factorily explained by quantitative growth in consumption. }\end{array}$ & SJM \\
\hline Wenlock, Buss, and Derry (1980) & UK & $\begin{array}{l}\text { Food wastage was significantly influenced by the composition of the } \\
\text { family, with adults wasting more in absolute terms than children, and } \\
\text { larger households wasting less per person than smaller households. }\end{array}$ & BJN \\
\hline $\begin{array}{l}\text { Harrison, Rathje, and Hughes } \\
\text { (1975) }\end{array}$ & USA & $\begin{array}{l}\text { The average household wasted between } \$ 80 \text { and } \$ 100 \text { worth of edible food } \\
\text { per year. }\end{array}$ & JNE \\
\hline
\end{tabular}

Note.-BFJ, British Food Journal; BJN, British Journal of Nutrition; CPH, Critical Public Health; FQP, Food Quality and Preference; IJCS, International Journal of Consumer Studies; JCB, Journal of Consumer Behavior; JCP, Journal of Cleaner Production; JEP, Journal of Experimental Psychology; JNE, Journal of Nutrition Education; LE, Local Environment; PO, PLOS One; RCR, Resources, Conservation and Recycling; SJM, Scandinavian Journal of Management; SOC, Sociology; TOCHI, ACM Transactions on Computer-Human Interaction; WM, Waste Management; WMR, Waste Management and Research.

in the literature, and it presents opportunities for future studies.

The literature does not profoundly discuss how the easy availability of food, in countries such as the United States and Brazil, might negatively affect food waste. Consumers tend to enjoy serving big portion sizes but at the same time are not always willing to repurpose the leftovers that remain on the table for reasons that go beyond the inability to reinvent a meal. Leftovers, in particular, can be conceptualized as "psychologically contaminated" or "used" food (Rozin 2014), and their use as limited to "thrifty meals" (Cappellini and Parsons 2012). As such, apart from the frugality and planning skills needed to reuse leftovers, consumers might avoid them due to the psychological contamination bias or simply because they want to show others that they can afford to eat always fresh food.

In a low-income context, food might be seen as wealth (Porpino et al. 2015), and other cultural factors also play a role in the promotion of food waste. The good-provider identity has been found and related to wasted food (GrahamRowe et al. 2014) and care as one of the cultural demands that promotes overprovisioning of healthy or comfort foods (Southerton and Yates 2015), which in turn increases the propensity of wasting leftovers. Empirical evidence of a "good mother" behavior as a driver of wasted food has been found in low-to-middle-income households in the United States (Porpino 2016).

The overpreparation pattern, justified by the willingness to save cooking time, seems to be driven by the enjoyment of having a table with plenty of food, as observed in Brazilian low-income families (Porpino et al. 2015). These households tend to overprepare food during weekdays to save food for the husband's lunch, packed for the next day, and Sunday lunches are considered family gatherings with plenty of homemade food. The combination of overpreparation and leftovers avoidance generates the basis for wasting rice and beans, the most consumed staple foods in Brazil. Rice and beans leftovers are commonly given to poultry or dogs.

Overall, there is a need to discuss more profoundly what is behind overpreparation, excessive purchase, stockpiling, and cooking routines. While individual aspects seem to 
Table 2. Future Research Recommendations Based on Previous Studies

Antecedents

Socio-demographic:

Children in the family (Tersptra et al. 2005)

Single household type (Koivupuro et al. 2012)

Woman responsible for grocery shopping (Koivupuro et al. 2012)

Higher number of younger people (Tucker and Farrelly 2015)

Higher household income (Stuart 2009; Gustavsson et al. 2011; Cox and Downing 2007)

Retail and marketing stimuli:

Offers and promotions (Cox and Downing 2007; Schneider 2008; Graham-Rowe et al. 2014)

Prepacked items (Graham-Rowe et al. 2014)

Large package size (Koivupuro et al. 2012; Williams et al. 2012; Ganglbauer et al. 2013)

In-store behavior / impulse buying (Parfitt et al. 2010)

Excessive purchasing (Harrison et al. 1975; Cox and Downing 2007; Koivupuro et al. 2012; Beretta et al., 2013; Ganglbauer et al. 2013; Graham-Howe 2013; Stefan et al. 2013)

Situational:

Long storage time / exceed expiration date or spoiled leftovers (Kantor 1997; Quested and Jonhson 2009; Williams et al. 2012)

Poor home economics skills (Cox and Downing 2007)

Lack of purchase planning (Schneider 2008; Parfitt et al. 2010; Evans 2011; Barilla 2012; Ganglbauer et al. 2013); lack of planning meals and food inventory (Stefan et al. 2013)

Lack of knowledge about food storage and handling (Terpstra et al. 2005; Parfitt et al. 2010; Koivupuro et al. 2012; Williams et al. 2012)

Supply knowledge and ability to locate food items (FarrWharton, Foth, and Choi 2014)

Wrong interpretation of food labels (Parfitt et al. 2010; Milne 2012; Abeliotis, Lasaridi, and Chroni 2014)

Dietary transition / more diversified diet (Parfitt et al. 2010)

Large plates / visual consumption norms (Wansink and van Ittersum 2013)

Behavioral and/or cultural:

Overpreparation (Blair and Sobal 2006; Cox and Downing 2007; Quested and Johnson 2009; Evans 2011; Gustavsson et al. 2011; Koivupuro et al. 2012; Williams et al. 2012; Beretta et al. 2013; Graham-Howe 2013; Porpino et al. 2015)

High sensitivity to food hygiene (Cox and Downing 2007); concern about food-borne illness (Neff, Spiker, and Truant 2015)

Good provider identity (Graham-Rowe et al. 2014; Porpino et al. 2015)

Domestic food practices (Evans 2011)

Low preference losses (Beretta et al. 2013)

Freshness preference (Neff et al. 2015)
Future research recommendations

Investigate the role of the one responsible for cooking most meals; incorporate food pantry users in field studies; explore whether low-income families (e.g., food stamps beneficiaries) waste more of certain food products.

Explore the relation between bulk-buying and food waste; incorporate an impulsivity scale in food waste studies; examine whether food products bought in abundance are comfort foods, staples, or convenience-driven.

Examine the relation between having a separate freezer and food waste; incorporate years of education as a variable; distinguish food labels across food products categories (e.g., refrigerated $\times$ nonrefrigerated foods); incorporate meal occasions as a variable to predict the option for using or not using leftovers; distinguish between preparing food for one's self or for others as an antecedent of acceptance to consume foods after "best before" dates.

Distinguish meal occasions (food for one's self vs. family meals) as a driver of overpreparation; incorporate parental indulgence as a variable to explain overpreparation; investigate the relation between overpreparation and status-signaling in the low-income context; examine if the good-provider identity is affected by caregiver type (mothers vs. grandmothers vs. fathers). 
Table 2. (Continued)

Antecedents

Feeling that food waste isn't a big problem (Graham-Rowe et al. 2014)

Perception that food waste isn't an individual responsibility (Graham-Rowe et al. 2014)

Prejudice against leftovers (Porpino et al. 2015)

Caring for a pet (Porpino et al. 2015)

Low food awareness (Parizeau, Massow, and Martin 2015)

Industry related:

Packages difficult to empty (Williams et al. 2012)
Future research recommendations
Examine if elderly consumers self-report food waste due to package issues. have been explored, the cultural context demands more attention. To discuss opportunities for filling these knowledge gaps, a future research agenda is presented.

If we consider that most research on this topic is being published in journals focused specifically on waste or food, it might be the case that a marketing or behavioral economics perspective is missing. Opportunities for future research are blossoming with the increasing awareness of the environmental consequences and costs of discarding food at the end of the food production and supply chain.

There are two predominant theoretical lenses adopted in food waste studies. Some published studies, such as Stefan et al. (2013), analyze food waste from an individual perspective and use the theory of planned behavior (Ajzen 1991). However, the followers of the social practice theories (Evans 2011; Ganglbauer et al. 2013; Southerton and Yates 2015) reject the emphasis on the micro level. This sociological perspective is useful in understanding the cultural context, but the consumer-focused perspective can also contribute to delineating nutritional education initiatives.

It might be the case that, instead of focusing solely on a given behavioral model, studies might be of greater theoretical contribution if they incorporate behavioral economics principles. Furthermore, behavioral economics could be useful in delineating more effective campaigns. Quested et al. (2013) mention that the complexity of consumer food waste behavior requires investigation of the issue from multiple disciplines, such as social research, economics, and systemthink approaches from within operational studies.

\section{Methodological Analysis}

A methodological analysis of papers published (table 3) also sheds light on avenues for future research. For instance, to the best of our knowledge, just one experiment was conducted to test the extent to which some variables affect wasted food. Cluster analysis is also absent from the literature. Over $40 \%$ of the papers are survey-based, and most of them only present descriptive statistics.

Table 3. Methodological Analysis of Household Food Waste Literature

$n$ $\%$

Type of study:

Empirical

Conceptual

20

83

Study design:

Survey

Interviews

Literature review

Ethnographic oriented

Experiment

4

17

Sample size:

$>500$

200-500

50-199

$<50$

46

17

17

17

4

8

25

12

Main analysis methods:

Descriptive

29

Descriptive stats/correlation $\quad 7 \quad 29$

Qualitative coding

$\chi^{2}$ tests/correlation

CFA/SEM

Regression

Analysis of variance 3 6 
It seems evident that more qualitative and mixedmethod studies are needed to clarify how certain cultural aspects affect food waste. As shown in table 4, further studies on how avoidance of leftovers and food abundance enjoyment, for example, generate waste might find plausible explanations through a cultural lens. Apart from theorizing, experiments could also be conducted with the aim of identifying effective communications strategies for behavioral change. This type of study could both fill theoretical gaps and contribute to nutritional education initiatives.

Food waste studies could also benefit from the application of structural equation modeling (SEM) to investigate the role of emotions in food disposal. There is empirical evidence linking stockpiling in abundance as being necessary to achieving peace of mind, overpreparation as a form of showing affection, and storage of leftovers as a delaying mechanism to mitigate the guilt associated with throwing away edible food. By testing a theoretical framework with SEM, authors could propose which emotions affect each stage of the food consumption process and which of them drive or mitigate food disposal.
Further theorizing is also needed to advance our understanding on how income affects food waste. Relatively little is known about the determinants of wasted food in the lower income context, and opportunities for future research should focus on better understanding this phenomenon in order to provide solutions for behavioral change. The commonsensical view that food waste is preponderant only among upper-middle classes should be questioned. If we consider that in certain cultures, food signals wealth, it might be the case that the pursuit of status promotes overpreparation, and thus it can be a driver of food waste among low-income families as well. It goes without mention that if we better understand the lower middle class, it is likely that a greater impact will be achieved, given the majority of consumers, worldwide, are in this segment.

The knowledge of consumer food waste, and even more importantly the identification of strategies that positively affect consumer behavior, is likely to advance with the conducting of more experiments. These studies might be closer to applied science than to mere theoretical contributions, which should not be seen as a drawback. For instance, ex-

Table 4. Shortcomings of Previous Studies and Suggestions

\begin{tabular}{ll}
\hline Shortcomings & Suggestions
\end{tabular}

Lack of analysis on the role of emotions

Inconsistent findings on how income relates to household food waste

Cultural factors lack explanations

Focus on marketing is missing

Lack of experiments to test the efficacy of strategies for behavioral change

Surveys with lack of analysis

Lack of methods to quantify household food waste
SEM as an analytical method could be useful to test how certain emotions (e.g., guilt and happiness) might relate to variables linked to wasted food.

Mixed-method studies could be conducted in two distinct areas, one being low income and another higher income to compare differences in both the amount of food wasted and drivers of waste.

Qualitative studies are still needed to more profoundly explain behaviors such as avoidance of leftovers and abundance enjoyment. Mixed-method approaches (qualitative and survey) could also be useful.

Most studies utilize a sociological lens, which is useful, but marketing insight is missing. Therefore, more focus on consumer behavioral factors (e.g., impulse buying) could shed light on underresearched aspects.

Experiments could be conducted to identify which interventions are likely to work better. Communications strategies, for instance, could be tested with the use of persuasion and subtle messages as well as new media versus traditional forms.

More analytical tools, such as cluster analysis, can help to identify consumer profiles that are more prone to waste food.

Mixed methods such as food waste diaries (self-reported) and analysis of garbage content could be combined to provide an improved estimation of household food waste. 
periments can compare and test which interventions work better to avoid food disposal in buffet restaurants.

The research opportunities identified are summarized in table 5 . In relation to food abundance, qualitative studies could clarify which cultural aspects might lead consumers to waste more food while quantitative methods can test moderating and/or mediating variables between leftovers abundance and wasted food.

Understanding the role of religion in relation to food waste might also contribute to explaining certain behaviors, given that food is often considered sacred. In addition, the process of preparing, serving, and discarding food in a household involves several emotions. How are they related to food waste? The current literature mentions guilt as a consequence of food waste, but more insights can be gleaned by investigating different emotions with the application of other methods.

Another research opportunity involves exploring the retail relationship with the consumer. Marketing communications, food-pricing strategies, and eating environments bias food consumption (Chandon and Wansink 2012). For instance, consumers are not always aware of some forms of marketing communications, such as the use of games on the Internet for introducing food products. Furthermore, lower income consumers are predominantly affected by temporary price promotions and quantity discounts (Chandon and Wansink 2012), which might be hypothesized as drivers of waste.

Thus, similarly to the analysis of food marketing in relation to obesity, it seems feasible to investigate whether marketing practices might be relevant antecedents of food waste. In both cases, win-win solutions could be proposed, in which retailers would increase profits (e.g., offering half-sized portions for a relatively higher price) and consumers would benefit from consuming fewer calories and wasting less.

\section{CONCLUSION}

Overall, there are opportunities to both expand the body of theory related to consumer food waste, which would help to explain and predict behavior, and to conduct studies aimed at fostering nutritional education campaigns. As an area of boundary research, food waste will most quickly evolve and make contributions to the extent it can develop rigorous taxonomies, discover new correlations between behaviors, and then systematically test these relationships (Wansink and van Ittersum 2016). Because of this, it is clear that a more standardized methodology to estimate consumer food waste is absent, and the results of this dif-

Table 5. Opportunities in Food Waste Research

$\begin{array}{ll}\text { Suggested topics } & \text { Research questions }\end{array}$

Food abundance and food waste

The role of marketing communications on food waste

Food waste in the low-income context in medium- and high-income nations

Environmental consciousness and food waste

Emotions and food waste

The role of religion in food waste

Communications initiatives for mitigating food waste

Social connectedness and food waste
Is food abundance promoting food waste? How do the different dimensions of food abundance affect food waste?

Is marketing making consumers waste more food? Are marketing, impulse buying, and food waste related?

Is food waste preponderant among the less privileged? Are there peculiar factors to the low-income context that led them to waste food?

How does environmental awareness affect food waste? Are more environmentally friendly consumers wasting less, or, for example, do households with composting bins tend to throw more leftovers away?

Can positive emotions (e.g., happiness and affection) have a negative impact on food waste? How do negative emotions (e.g., guilt and sadness) relate to waste?

Are consumers who are more religious less wasteful? Do more religious people experience more guilt when food is wasted? Are there significant differences between distinct religious practices?

Do consumers respond better to persuasive techniques or to subtle messages? How likely are consumers to adopt new technologies (e.g., APP) and be influenced by them?

Are more socially connected households wasting more or less food? What drives and mitigates food waste in such scenarios? 
ficulty in measuring are fragmented and inconsistent estimations of consumer food waste. While reliable estimations can point to where action is needed, it is likely that experiment-based research can contribute to theoretical advances, given the prevalence of surveys to investigate this phenomenon. More ethnographic-oriented studies can also shed light on overlooked cultural factors, as indicated by figure 2.

As figure 2 shows, behavioral research can be a driver of change if an understanding of how to frame messages to change behavior is gained. It is herein postulated that acquiring science-based data with more empirical research will contribute to an improved understanding of the phenomenon; a prerequisite to advancing to the next level is a sustainable consumption paradigm. The proposed framework does not comprehensively incorporate all of the research opportunities presented but summarizes what may be seen as the core lines of research that demand further study. Future research recommendations related to the role of retail and marketing stimuli on food waste, as detailed in table 2, could make use of both experimental research and ethnographic-oriented methods.

The subsequent conclusion reiterates the growing importance of aligning academically oriented research with solutions that positively affect society as a whole. In this sense, food waste is a research topic that deserves attention, given the tremendous amount of food loss worldwide at every stage of the food chain. By identifying research opportunities and proposing methods for assessing the problem, this commentary is aimed at providing avenues for rigorous and relevant research.

\section{THE LARGER THEME: HUNGER AND SATIETY}

Food waste studies should not be considered as too narrow. The ability to show how an apparently narrow topic relates to a larger theme increments the contributions, moving the research into a wider area of influence (van Ittersum and Wansink 2016). If we consider that wasting edible food might contribute to infringing on opportunities for others to feed themselves, then there is a link between this phenomenon and hunger relief programs. Often unmentioned is the need to improve our understanding of how lowincome families, such as the beneficiaries of food stamps initiatives, consume food products.

Improving our understanding of household food waste in the low-income segment can shed light on another underresearched issue: hidden hunger, a major public health problem in developing nations caused by a lack of essential vitamins and minerals in given diets. Individuals suffering from this may even be overweight, due to the high consumption of staple foods such as rice and maize but without appropriate access to fruits, vegetables, and proteins, which provide important micronutrients for their health and well-being (CGIAR 2015). It is interesting to note that

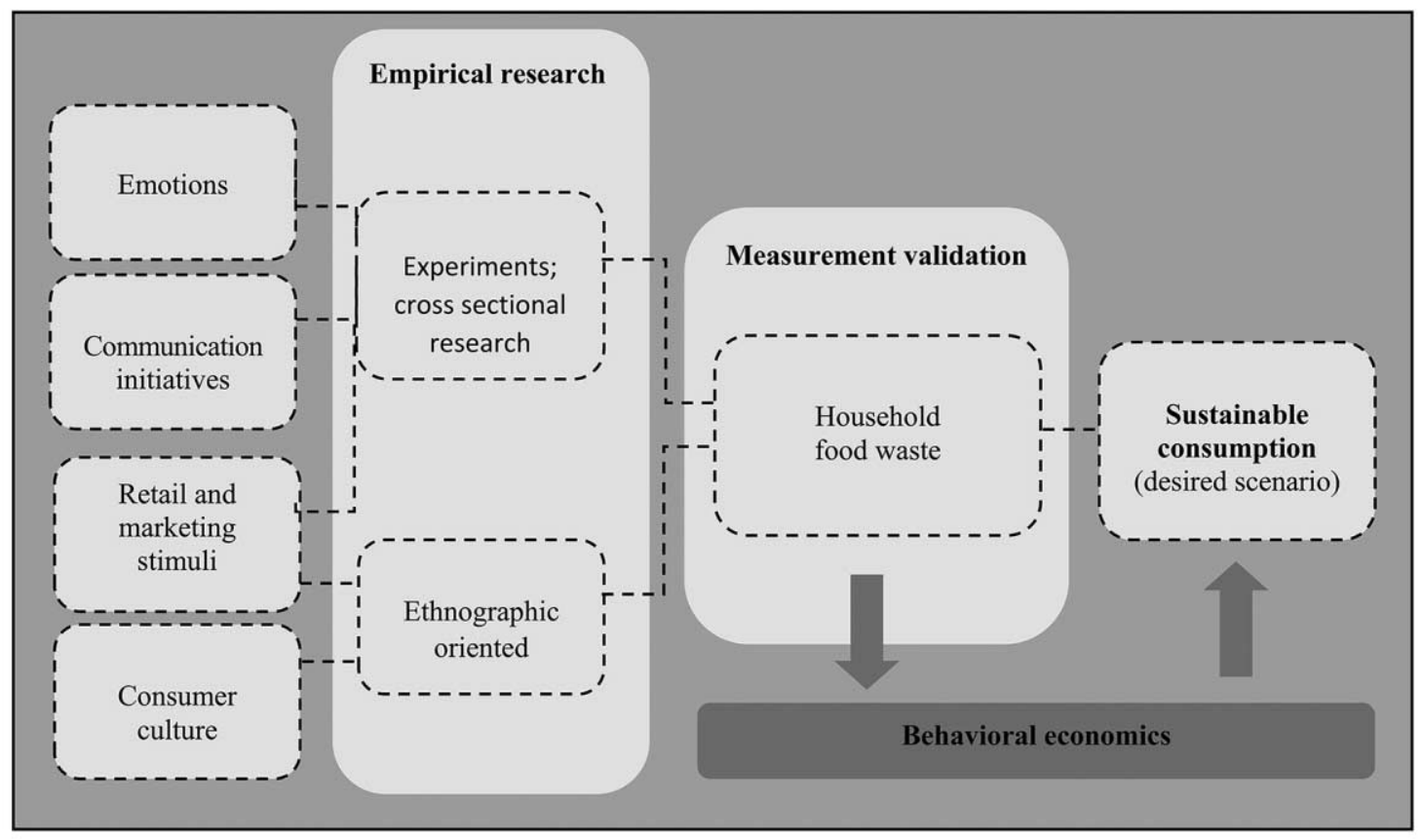

Figure 2. Framework for future research on food waste. 
a question that demands explanation concerns whether or not hidden hunger and food waste may coexist in certain households.

When it comes to satiety, evidence drawn from previous studies leads to the postulation that consumers may face a dilemma between overeating and wasting food. This problem demands further investigation and may be studied beyond the context of economic development. For instance, obesity is no longer a problem related to the more affluent segment, and abundance of staples is prevalent in some low-income regions.

\section{REFERENCES}

Abeliotis, Konstadinos, Katia Lasaridi, and Christina Chroni (2014), "Attitudes and Behaviour of Greek Households regarding Food Waste Prevention," Waste Management and Research: The Journal of the International Solid Wastes and Public Cleansing Association, ISWA, 32 (February), 23740.

Ajzen, Icek (1991), “The Theory of Planned Behavior," Organizational Behavior and Human Decision Processes, 50 (2), 179-211.

Beretta, Claudio, Franziska Stoessel, Urs Baier, and Stefanie Hellweg (2013), "Quantifying Food Losses and the Potential for Reduction in Switzerland," Waste Management (New York, NY), 33 (3), 764-73.

Blair, Dorothy, and Jeffery Sobal (2006), "Luxus Consumption: Wasting Food Resources through Overeating," Agriculture and Human Values, 23 (1), 63-74.

Bolaane, Bejanmin, and Mansoor Ali (2004), "Sampling Household Waste at Source: Lessons Learnt in Gaborone," Waste Management and Research: The Journal of the International Solid Wastes and Public Cleansing Association, ISWA, 22 (3), 142-48.

Cappellini, Benedetta, and Elizabeth Parsons (2012), "The Thrifty Meal: Re-creating Value in the Kitchen," Advances in Consumer Research, 40 (2), 739-40.

CGIAR (2015), "What Is Hidden Hunger?" http://biofortconf.ifpri.info /files/2014/03/What-is-Hidden-Hunger-Fact-Sheet_3-27-2014.pdf.

Chandon, Pierre, and Brian Wansink (2012), "Does Food Marketing Need to Make Us Fat? A Review and Solutions," Nutrition Reviews, 70 (10), 571-93.

Cox, Jayne, and Phil Downing (2007), "Food Behaviour Consumer Research: Quantitative Phase," WRAP, Banbury, UK, http://www.wrap .org.uk/downloads/Food_behaviour_consumer_research_quantitative _jun_2007.0a80ed7d.6393.pdf.

Ekström, Karin M., ed. (2015), Waste Management and Sustainable Consumption, London: Routledge.

European Commission (2010), "Preparatory Study on Food Waste across EU 27," technical report, http://ec.europa.eu/environment/eussd/pdf /bio_foodwaste_report.pdf.

Evans, David (2011), "Blaming the Consumer-Once Again: The Social and Material Contexts of Everyday Food Waste Practices in Some English Households," Critical Public Health, 21 (4), 429-40.

- (2012a), "Beyond the Throwaway Society: Ordinary Domestic Practice and a Sociological Approach to Household Food Waste," Sociology, 46 (1), 41-56.

_ (2012b), "Binning, Gifting and Recovery: The Conduits of Disposal in Household Food Consumption," Environment and Planning D: Society and Space, 30 (6), 1123-37.
FAO (2013), "Food Wastage Footprint: Impact on Natural Resources," summary report, Food and Agriculture Organization of the United Nations, Rome, http://www.fao.org/docrep/018/i3347e/i3347e.pdf.

- (2014), "Conclusions of the Regional Experts: Consultation on Food Losses and Waste," Food and Agriculture Organization of the United Nations, Santiago.

Farr-Wharton, Geremy, Marcus Foth, and Jaz Hee-Jeong Choi (2014), "Identifying Factors That Promote Consumer Behaviours Causing Expired Domestic Food Waste," Journal of Consumer Behavior, 13 (6), 393-402.

Foresight (2011), "The Future of Food and Farming: Challenges and Choices for Global Sustainability," Final Project Report, The Government Office for Science, London.

Ganglbauer, Eva, Geraldine Fitzpatrick, and Rob Comber (2013), "Negotiating Food Waste: Using a Practice Lens to Inform Design," ACM Transactions on Computer-Human Interaction, 20 (2), 1-25.

Graham-Rowe, Ella (2013), "Carbon Foodprint," SPLASH (blog), University of Sussex, http://splash.sussex.ac.uk/blog/for/psychresearch/by/tag /phd.

Graham-Rowe, Ella, Donna Jessop, and Paul Sparks (2014), "Identifying Motivations and Barriers to Minimising Household Food Waste," Resources, Conservation and Recycling, 84 (March), 15-23.

Grizzetti, Bruna, Ugo Pretato, Luis Lassaletta, Gilles Billen, and Josette Garnier (2013), "The Contribution of Food Waste to Global and European Nitrogen Pollution," Environmental Science and Policy, 33 (November), 186-95.

Gustavsson, Jenny, Christel Cederberg, Ulf Sonesson, Robert van Otterdijk, and Alexandre Meybeck (2011), "Global Food Losses and Food Waste: Extent, Causes and Prevention," report, Food and Agriculture Organization of the United Nations, Rome.

Harrison, Gail, William Rathje, and Wilson Hughes (1975), "Food Waste Behavior in an Urban Population," Journal of Nutrition Education, 7 (1), 13-16.

Kantor, Linda, Kathryn Lipton, Alden Manchester, and Victor Oliveira (1997), "Estimating and Addressing American Food Loss," Food Review, 20 (1), 2-12.

Katsarova, Ivana (2014), “Tackling Food Waste: The EU's Contribution to a Global Issue,” report, European Parliamentary Research Service, Strasbourg, France.

Koivupuro, Heta-Kaisa, Hanna Hartikainen, Kirsi Silvennoinen, Juha-Matti Katajajuuri, Noora Heikintalo, Anu Reinikainen, and Lotta Jalkanen (2012), "Influence of Socio-Demographical, Behavioural and Attitudinal Factors on the Amount of Avoidable Food Waste Generated in Finnish Households," International Journal of Consumer Studies, 36 (2), 18391.

Leal Filho, Walter, and Marina Kovaleva (2015), Food Waste and Sustainable Food Waste Management in the Baltic Sea Region, Hamburg: Springer.

Milne, Richard (2012), "Arbiters of Waste: Date Labels, the Consumer and Knowing Good, Safe Food," Sociological Review, 60 (S2), 84-101.

Nahman, Anton, Willem de Lange, Suzan Oelofse, and Linda Godfrey (2012), "The Costs of Household Food Waste in South Africa," Waste Management (New York, NY), 32 (11), 2147-53.

Neff, Roni A., Marie Spiker, and Patricia Truant (2015), "Wasted Food: U.S. Consumers' Reported Awareness, Attitudes, and Behaviors," PLOS One, 10 (6), 1-16.

Oelofse, Susan, and Anton Nahman (2013), "Estimating the Magnitude of Food Waste Generated in South Africa," Waste Management and Research: The Journal of the International Solid Wastes and Public Cleansing Association, ISWA, 31 (1), 80-86. 
Parfitt, Julian, Mark Barthel, and Sarah Macnaughton (2010), "Food Waste within Food Supply Chains: Quantification and Potential for Change to 2050," Philosophical Transactions of the Royal Society Biological Sciences, 365 (1554), 3065-81.

Parizeau, Kate, Mike von Massow, and Ralph Martin (2015), "HouseholdLevel Dynamics of Food Waste Production and Related Beliefs, Attitudes, and Behaviours in Guelph, Ontario," Waste Management, 35 (January), 207-17.

Porpino, Gustavo (2016), "Wasted Positive Intentions: The Impact of Affection and Abundance on Household Food Waste," forthcoming.

Porpino, Gustavo, Juracy Parente, and Brian Wansink (2015), "Food Waste Paradox: Antecedents of Food Disposal in Low-Income Households," International Journal of Consumer Studies, doi:10.1111/ijcs .12207 .

Quested, T. E., E. Marsh, D. Stunell, and A. D. Parry (2013), "Spaghetti Soup: The Complex World of Food Waste Behaviours," Resources, Conservation and Recycling, 79 (October), 43-51.

Rozin, Paul (2014), "Psychological Basis of Food Wasting Behavior," paper presented at the Last Food Mile Conference, University of Pennsylvania, December 8-9, Philadelphia.

Schneider, F. (2008), "Wasting Food—an Insistent Behavior," paper presented at Waste, the Social Context: Urban Issues and Solutions, May 11-15, Edmonton.

Silvennoinen, Kirsi, Juha-Matti Katajajuuri, Hanna Hartikainen, Lotta Heikkila, and Anu Reinikainen (2014), "Food Waste Volume and Composition in Finnish Households," British Food Journal, 116 (6), 105868.

Southerton, Dale, and Luke Yates (2015), “Exploring Food Waste through the Lens of Social Practice Theories: Some Reflections on Eating as a Compound Practice," in Waste Management and Sustainable Consumption, ed. Karin M. Ekström, London, 133-49.

Stefan, Violeta, Erica van Herpen, Ana Alina Tudoran, and Liisa Lähteenmäki (2013), "Avoiding Food Waste by Romanian Consumers: The Importance of Planning and Shopping Routines," Food Quality and Preference, 28 (1), 375-81.
Stuart, Tristram (2009), Waste: Uncovering the Global Food Scandal, New York: Norton.

Terpstra, M. J., L. P. A. Steenbekkers, N. C. M. Maertelaere, and S. Nijhuis (2005), "Food Storage and Disposal: Consumer Practices and Knowledge," British Food Journal, 107 (7), 526-33.

Thogersen, John (1996), "Wasteful Food Consumption: Trends in Food and Packaging Waste," Scandinavian Journal of Management, 12 (3), 291-304.

Tucker, C. A., and T. Farrelly (2015), "Household Food Waste: The Implications of Consumer Choice in Food from Purchase to Disposal," Local Environment: The International Journal of Justice and Sustainability, doi:10.1080/13549839.2015.1015972.

Vanham, D., F. Bouraoui, A. Leip, B. Grizzetti, and B. Bidoglio (2015), "Lost Water and Nitrogen Resources due to EU Consumer Food Waste," Environmental Research Letters, 8 (10), 1-15.

van Ittersum, Koert, and Brian Wansink (2016), "The Behavioral Science of Eating: Encouraging Boundary Research That Has Impact," Journal of the Association for Consumer Research, 1 (1), in this issue.

Wansink, Brian, and Koert van Ittersum (2013), "Portion Size Me: PlateSize Induced Consumption Norms and Win-Win Solutions for Reducing Food Intake and Waste," Journal of Experimental Psychology: Applied, 19 (4), 320-32.

(2016), "Boundary Research: Tools and Rules to Impact Emerging Fields," Journal of Consumer Behaviour, 15 (2), forthcoming.

Wenlock, R. W., D. H. Buss, and B. J. Derry (1980), "Household Food Wastage in Britain," British Journal of Nutrition, 43, 53-70.

West, Paul C., James Gerber, Peder Engstrom, Nathaniel Mueller, Kate Brauman, Kimberly Carlson, Emily Cassidy, Matt Johnston, Graham MacDonald, Deepak Ray, and Stefan Siebert (2014), "Leverage Points for Improving Global Food Security and the Environment," Science, 345 (6194), 325-28.

Williams, Helén, Fredrik Wikström, Tobias Otterbring, Martin Löfgren, and Anders Gustafsson (2012), "Reasons for Household Food Waste with Special Attention to Packaging," Journal of Cleaner Production, 24 (March), 141-48.

\section{Commentary: Waste Not, Want Not: Can Consumer Behavior Research Help Reduce Food Waste?*}

JOANNE F. GUTHRIE

See "Household Food Waste Behavior: Avenues for Future Research" by Porpino, in this issue

Despite its association with unlovely images of half-eaten food and moldy vegetables left forgotten in the far reaches of the refrigerator, food waste has become a hot topic. As Porpino (2016) notes, the public has become more aware that wasted food represents a misuse of environmental resources. His emphasis on understanding the consumer role in food loss is well placed. In 2010, 133 billion pounds, or
31 percent of the 430 billion pounds of food available in the United States at the retail or consumer level, went uneaten (Buzby et al. 2013). Some of this loss, such as shrinkage during cooking, is unavoidable, while other losses, such as discarding food in dented cans, are necessary to food safety. However, losses also include safe, wholesome food (US EPA 2015); loss of such foods could potentially be re- 